\title{
ANALISIS RASIO ARUS KAS UNTUK MENILAI KINERJA KEUANGAN PADA KOPERASI KARYAWAN ANGKASA PURA 1 "SELAPARANG" BANDARA INTERNASIONAL ZAINUDIN ABDUL MAJID
}

\author{
Lalu Jamhuri Hidayat \\ Jurusan Akuntansi Sekolah Tinggi IImu Ekonomi AMM Mataram \\ sasakhidayat@gmail.com \\ I Nengah Arsana \\ Jurusan Akuntansi Sekolah Tinggi IImu Ekonomi AMM Mataram \\ arsana.inengah@yahoo.co.id \\ Ni Nyoman Yuliati \\ Jurusan Akuntansi Sekolah Tinggi IImu Ekonomi AMM Mataram \\ ninyomanyuliati@yahoo.com
}

\begin{abstract}
ABSTRAK:
Penelitian ini bertujuan untuk mengetahui perkembangan dan kinerja laporan arus kas Kokapura Selaparang berdasarkan laporan arus kas tahun 2014-2018. Jenis penelitian ini deskriptif dengan pendekatan kuantitatif. Teknik pengumpulan data yang digunakan adalah Teknik dokumentasi dan wawancara. Objek penelitian berupa data neraca, laporan laba-rugi, laporan arus kas dan alokasi pembagian Sisa Hasil Usaha serta gambaran umum koperasi di tahun 2014-2018.

Teknik analisis data yang digunakan adalah analisis rasio arus kas yang terdiri dari rasio Arus Kas Operasi (AKO), rasio Cakupan Arus Dana $(C A D)$, rasio Cakupan Kas terhadap Bunga (CKB), rasio Cakupan Kas terhadap HutangLancar (CKHL), rasio Pengeluaran Modal (PM), rasio Total Hutang (TH), rasio Arus Kas Bersih Bebas (AKBB) dan rasio Kecukupan Arus Kas (KAK).

Kinerjan keuangan Kokapura Selaparang tahun 2014-2018 dinilai dari rasio laporan arus kas dinyatakan cukup baik, kinerjanya di katakana cukup baik karena dari perhitungan kedelapan rasio arus kas di atas menyatakan bahwa rasio memenuhi standar 1 , dan hanya 4 rasio yang tidak memenui standar1. Rasio yang tidak memenuhi standar yakini rasio Arus Kas Operasi (AKO), Cakupan Kas terhadap Hutang Lancar (CKHL), Total Hutang (TH) dan Kecukupan Arus Kas (KAK). Dan rasio yang sudah memenuhi standar yakni Cakupan Arus Dana (CAD), Pengeluaran Modal (PM), dan Arus Kas Bersih Bebas (AKBB). Dalam hal ini Koperasi tidak mampu membayar kemampuan kewajiban lancar dan serta kurang mampu menyediakan kas untuk memenuhi kewajibannya. Kokapura Selaparang harus mampu meningkatkan arus kas dari aktivitas operasi agar kewajiban jangka pendek
\end{abstract}


terpenuhi, memaksimalkan dan mengelolaarus kas dari pendanaan yang didapat dari anggota agar proses swadaya tetap dapat dilakukan.

Kata Kunci : RasioArus Kas, KinerjaKeuangan.

\section{Abstract}

This research aim to to know cash flow statement performance and growth of KokapuraSelaparang pursuant to year cash flow statement 20142018. this descriptive Research type with quantitative approach. Technique data collecting the used Technique interview and documentation. Research object in the form of balance data, loss and profit report, cash flow statement and allocation of division of Net income and also common picture of co-operation in year 2014-2018.

Technique analyse data the used [is] cash flow ratio analysis which consist of Cash Flow Operation ratio ( $A K O$ ), Coverage Fund Flow ratio ( $C A D)$, Coverage Cash ratio to Flower ( $C K B)$, Coverage Cash ratio to Current Liabilities (CKHL), Capital Expenditure ratio ( PM), Total Liabilities ratio ( TH), Free Clean Cash Flow ratio ( $A K B B$ ) and ratio Sufficiency of Cash Flow (KAK).

Monetary performance of KokapuraSelaparang in year 2014-2018 assessed from cash flow statement ratio expressed is good enough, its performance [in] telling good enough because from eight calculation of cash flow ratio above expressing that 3ratio fulfill standard 1, and only 4 ratio which [is] menu [do] not standard 1. Ratio which [do] not fulfill standard namely Cash Flow Operation ratio ( $A K O$ ), Coverage Cash to Current Liabilities ( CKHL) and Total Liabilities ( TH) and Sufficiency Of Cash Flow ( $K A K)$. And ratio which have fulfilled standard namely Coverage Fund Flow ( CAD), Coverage Cash to Flower (CKB), Capital Expenditure ( PM), and Free Clean Cash Flow ( AKBB. In this case Co-Operation unable to pay [for] ability of fluent obligation and and also indigent provide cash to fulfill its obligation. KokapuraSelaparang have to can improve cash flow of activit operate for [so that/ to be] obligation short-range fufilled, maximizing and managing cash flow of got financing of member [so that/ to be] self-supporting.

Keyword : Ratio Cash Flow, Monetary Performance,

\section{PENDAHULUAN}

\section{Latar Belakang}

Perkembangan zaman yang begitu cepat pada saat ini menuju era digital, tidak dapat dibendung. Percepatan ini mendorong dunia usaha untuk dapat mengimbangi kemajuan zaman serta pola prilaku masyarakat yang hedonis agar tidak di tinggal oleh zaman. Dalam kegiatan dunia usaha di Indonesia, ada berbagai bentuk badan hokum perusahaan yaitu: 
Perusahaan Perseorangan; Persekutuan seperti Firma dan Persekutuan Komanditer; PeseroanTerbatas; Badan Usaha Milik Negara; Badan Usaha Milik Daerah; dan Koperasi. Bentuk-bentuk kegiatan usaha tersebut, selanjutnya dikelompokkan dalam 3 sektor, yaitu: Usaha Swasta, Usaha Pemerintah, dan Koperasi.

Sesuai dengan UU No. 25 tahun 1992 tentang koperasi. Koperasi ialah suatu badan usaha yang beranggotakan orang- orang atau badan hukum, dengan melandaskan kegiatannya berdasarkan prinsip koperasi yang sekaligus sebagai gerakan ekonomi rakyat yang berdasarkan pada asas kekeluargaan. Ditinjau dari UU NO12Tahun 1967 mengenai jenis - jenis koperasi yang tercantum di dalam pasal 17 bagian 6 yang isinya memuat, jenis - jenis Koperasi berdasarkan lapangan usahanya Koperasi Konsumsi, Koperasi Simpan Pinjam, Koperasi Produksi dan Koperasi Serba Usaha.

Sifat kas yang sangat rentan dengan penyelewengan yang dapat mempengaruhi kinerja koperasi yang mengakibatkan kemuduran koperasi tersebut dalam mengelola koperasi. Jumlah koperasi tidak aktif kian banyak, factor utama yang menyebabkan jumlah koperasi tidak aktif terus meningkat diprediksi karena salah pengelolaan. Banyak koperasi muncul berdasarkan coba-coba sehingga ketika berjalan baru menyadari salah memilih bidang usaha. Selainitu, peranan anggota koperasi kurang dan hanya semangat saat proses mendirikan saja sehingga dalam perjalanannya tanpa rah, ada beberapa faktor yang membuat koperasi bermasalah. Selain factor permodalan, keberadaan unit usaha ini juga terkendala sumber daya manusia. Seringkali kurangnya pengetahuan dalam pengelolaan dan keterbatasan SDM membuat jalannya koperasi jad itersendat dan kemudian jadi matisuri.

Dalam Laporan Sisa Hasil Usaha (SHU) dan Nilai Aset yang dikukuhkan KOKAPURA yang terus meningkat dari tahun ketahun yang mencerminkan pertumbuhan koperasi, seperti table berikut:

Tabel 1

Sisa Hasil Usaha dan AsetKokapura "Selaparang"

\begin{tabular}{|l|c|l|c|l|}
\hline Tahun & $\begin{array}{c}\text { Aset } \\
(\mathrm{Rp})\end{array}$ & $\begin{array}{c}\text { Persentase } \\
\text { kenaikan }\end{array}$ & $\begin{array}{c}\text { Sisa Hasil Usaha } \\
(\mathrm{Rp})\end{array}$ & $\begin{array}{c}\text { Persentase } \\
\text { kenaikan }\end{array}$ \\
\hline 2015 & $1.528 .811 .762,38$ & - & $170.055 .395,44$ & - \\
\hline 2016 & $1.752 .939 .968,59$ & $14,66 \%$ & $508.318 .056,63$ & $199 \%$ \\
\hline 2017 & $2.307 .362 .578,83$ & $31,63 \%$ & $691.830 .846,89$ & $36 \%$ \\
\hline 2018 & $3.044 .661 .505,48$ & $31,95 \%$ & $808.525 .999,54$ & $17 \%$ \\
\hline
\end{tabular}

Sumber: Lampiran Laporan Pertanggung Jawaban Pengurus

Akan tetapi kenaikan ini dilihat dari persentase kenaikan dan penurunan dari tahun 2015 sampai 2018. Peningkatan SHU yang tertinggi terjadi pada tahun 2016 sebesar 199\% dan peningkatan terendah terjadi pada tahun 2018 yakni hanya sebesar $17 \%$. 
Tabel 2

Modal sendiri dan Kewajiban

\begin{tabular}{|l|c|l|c|l|}
\hline Tahun & $\begin{array}{c}\text { Modal Sendiri } \\
(\mathrm{Rp})\end{array}$ & $\begin{array}{l}\text { Persentase } \\
\text { kenaikan }\end{array}$ & $\begin{array}{c}\text { Kewajiban } \\
(\mathrm{Rp})\end{array}$ & Persentasekenaikan \\
\hline 2015 & 2.689 .961 .565 & - & 1.741 .004 .461 & - \\
\hline 2016 & 2.767 .923 .420 & $2,90 \%$ & 1.884 .863 .858 & $8,26 \%$ \\
\hline 2017 & 3.248 .029 .536 & $17,35 \%$ & 2.493 .993 .837 & $32,32 \%$ \\
\hline 2018 & 4.092 .293 .839 & $25,99 \%$ & 1.795 .312 .442 & $-28,01 \%$ \\
\hline
\end{tabular}

Sumber: Lampiran Laporan Pertanggung Jawaban Pengurus

Namun disisi lain kenaikan aset dan modal sendiri tidak diikuti dengan total kewajiban dimana kewajiban koperasi KOKAPURA boleh dikatakan mengalami fluktuasi yakni pada tahun 2016-2017 mengalami peningkatan akan tetapi di tahun 2018 mengalami penurunan sebesar Rp.1.795.312.442 atau $-28,01 \%$.

Berdasarkan tabel 1 dan tabel 2 yang menjelaskan persentase kenaikan mengalami penurunan. Dan total kewajiban yang boleh dikatakan mengalami fluktuasi. Maka dari itu kinerja koperasi perlu dikaji lebih lanjut, yang lebih khusus yaitu kinerja Arus Kas yang terkait dengan pendanaan. Dengan judul "Analisis Rasio Arus Kas untuk Menilai Kinerja Keuangan Pada Koperasi Karyawan Angkasa Pura 1 "Selaparang" Bandara Internasional Zainudin Abdul Majid".

\section{TINJAUAN PUSTAKA}

\section{Pengertian Koperasi}

Menurut UU Nomor 25 Tahun 1992 Pasal 1 ayat (1) (2005:1) tentang Perkoperasian: "Koperasiadalah badan usaha yang beranggotakan orangorang atau badan hokum koperasi dengan melandaskan kegiatannya berdasarkan prinsip - prinsip koperasi sekaligus sebagai gerakan ekonomi rakyat yang berdasarkan atas asas kekeluargaan."

\section{Jenis-JenisKoperasi}

Secara garis besar menurut Anoraga dan Widiyanti (2007:19), jenis koperasi yang ada dapat kita bagi menjadi 5 golonganyaitu:

1. Koperasi Konsumsi

2. Koperasi Kredit atau Koperasi Simpan Pinjam

3. Koperasi Produksi

4. Koperasi Jasa

5. Koperasi Serba Usaha

\section{Pengertian Laporan Arus Kas}

Laporan arus kas yaitul aporan yang melaporkan penerimaan kas, pembayaran kas, dan perubahan bersih pada kas yang berasal dari aktivitas operasi, investasi dan pendanaan dari suatu perusahaan selama satu 
periode dalam suatu format yang merekonsiliasis aldo kas awal dan saldo kas akhir periode. (Kieso:2008).

\section{Tujuan Laporan Arus Kas}

Laporanarus kas (cash flow) diharapkan mampu menjelaskan tentang bagaimana kas dihasilkan dan digunakan. Laporan ini juga sekaligus untuk mengatasi kekurangan laporanl aba-rugi yang menggunakan basis akrual (Prihadi, 2011:77).

\section{PenyajianLaporanArus Kas}

Menurut Jusup (2011), laporan arus kas mengklasifikasikan penerimaan kas dan pengeluaran kas menjadi aktivitas operasi, investasi dan pendanaan.

a. AktivitasOperasi

Aktivitas operasi meliputi pengaruh kas dari transaksi yang menimbulkan pendapatan dan beban.

b. Aktivitas Investasi

Dalam SAK-ETAP (2013:24), arus kas dari investasi mencerminkan pengeluaran kas sehubungan dengan sumber daya yang bertujuan untuk menghasilkan pendapatan dan arus kas masa depan.

c. Aktivitas Pendanaan

Menurut Jusup (2011), aktivitas pendanaan meliputi:

1. Mendapatkan kas dari penerbitans urat utang

2. Mendapatkan kas dari pemegang saham,

\section{Metode Penyusuna LaporanArus Kas}

Menurut Rudianto (2012:198), secara umum terdapat dua metode dalam menyusun laporan arus kas:

a. Metode Langsung

b. Metode Tidak Langsung

\section{AnalisisLaporan Arus Kas}

Menurut Darsono dan Ashari (2005:91), Alat analisis rasio laporan arus kas yang diperlukan untuk menilai kinerja keuangan perusahaan antara lain:

1. RasioArus Kas Operasi (AKO)

2. Rasio Total Hutang (TH)

3. Rasio Pengeluaran Modal (PM)

4. Rasio Cakupan Arus Dana (CAD)

5. Rasio Cakupan Kas Terhadap Bunga (CKB)

6. Rasio Cakupan Kas Terhadap Hutang Lancar (CKHL)

7. Rasio Kecukupan Arus Kas (KAK)

8. Rasio Arus Kas Bersih Bebas (AKBB) 


\section{Kerangka Konseptual}

Kerangka konseptual merupakan model konseptual tentang bagaimana teori berhubungan dengan berbagai faktor yang telah diidentifikasi sebagai masalah yang penting (Sekaran,1992 dalam Sugiyono, 2015:60).

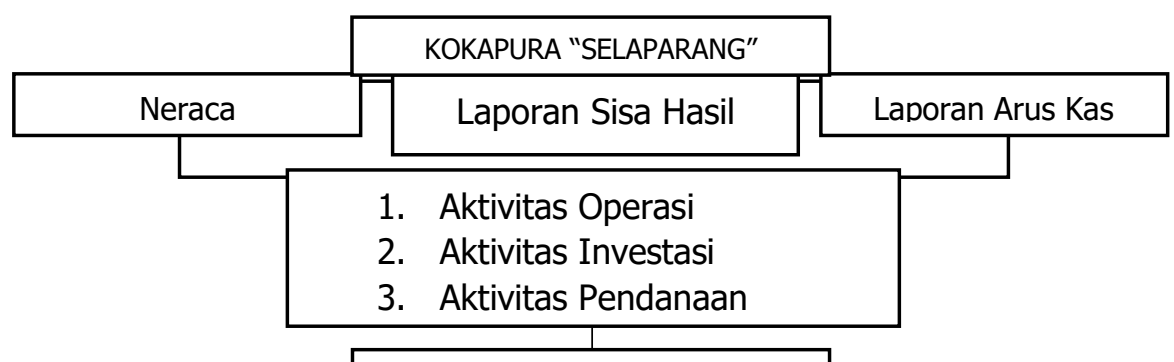
Analisis Rasio Arus Kas
Kesimpulan
Gambar 1
Kerangka Konseptual

\section{JenisPenelitian}

Jenis penelitian ini adalah deskriptif. MenurutSugiyono (2012: 54) "penelitian deskriptif suatu metode dalam meneliti status sekelompok manusia, suatu objek, suatu kondisi, suatu system pemikiran, ataupun suatu peristiwa pada masa sekarang.

\section{Teknik Pengumpulan Data}

Teknik pengumpulan data yang digunakan penelitiadalah:

1. Wawancara (interview), yaitu peneliti memperoleh keterangan dengan cara melakukan Tanya jawab dengan pihak-pihak terkait

2. Studi Dokumentasi, yaitu dengan mengumpulkan data teori-teori yang berhubungan dengan laporan arus.kas

\section{Jenis dan Sumber Data}

1. Jenis Data Jenis data yang digunakan peneliti adalah data kuantitatif. Data kuantitatif yaitu data yang merupakan kumpulan dari data angkaangka

2. Sumber Data

Sumber data yang digunakan dalam penelitian ini berupa data sekunder, yaitu data yang diperoleh atau dikumpulkan peneliti dari berbagai sumber yang telah ada. 


\section{Indentifikasi \& DefinisiOperasionalVariabel}

\section{IndentifikasiVariabel}

Adapun beberapa operasional variable dalam penelitian ini yang memberikanin formasi tentang judul penelitian ini antara lain:

1. Rasio Likuiditas Arus Kas Operasi

- Rasio Arus Kas Operasi

- Rasio Cakupan Dana

- Rasio Cakupan Kas terhadapBunga

- Rasio Cakupan Kas terhadap Hutang Lancar

- Rasio Pengeluaran Modal

- Rasio Total Hutang

2. Rasio Fleksibilitas Arus Kas

- Rasio Arus Kas Bersih Bebas

- Rasio Kecukupan Arus Kas

\section{DefinisiOperasionalVariabel}

Adapun definisi dari operasional variable dalam penelitian ini yang memberikanin formasi tentang judul penelitian ini antara lain:

1. Rasio Likuiditas Arus Kas Operasi

- Rasio Arus Kas Operasi (AKO)

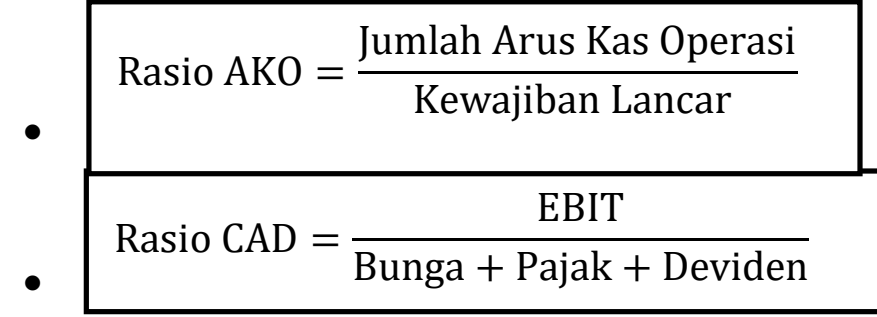

- $\quad$ Rasio Cakupan Kas Bunga $=\frac{\text { Arus Kas Operasi }+ \text { Bunga }+ \text { Pajak }}{\text { Bunga }}$

- Rasio CKHL $=\frac{\text { Jumlah Kas Operasi }+ \text { Deviden Kas }}{\text { Hutang Lancar }}$

Rasio Pengeluaran Modal $=\frac{\text { Arus Kas Operasi }}{\text { Pengeluaran Modal }}$

-

$$
\text { Rasio Total Hutang }=\frac{\text { Arus Kas Operasi }}{\text { Total Hutang }}
$$

2. RasioFleksibilitasArus Kas

- RasioArus Kas BersihBebas (AKBB)

$$
\begin{aligned}
& \text { Laba Bersih + Bunga + Depresiasi }+ \text { Sewa }+ \\
& \text { Rasio AKBB }=\frac{\text { Leasing }+ \text { Deviden }+ \text { Peng. Modal }+ \text { Sewa }}{\text { Biaya Bunga }+ \text { Sewa }+ \text { Hutang JK panjang }} \\
& \text { +Kewajiban Leasing }
\end{aligned}
$$


- RasioKecukupanArus Kas (KAK)

$$
\text { Rasio KAK }=\frac{\text { EBIT }- \text { Bunga }- \text { Pajak }- \text { Pengeluaran Modal }}{\text { Rata }- \text { rata Hutang Lancar }}
$$

\section{Teknik Analisis Data}

Teknik analisis data yang digunakan dalam penelitian ini adalah Teknik deskriptif. Menurut Sugiyono (2012:24), "deskriptif, yaitu teknik yang menggolongkan, menganalisis dan menginterpretasikan data yang diperoleh sehingga dapat memberikan gambaran yang jelas mengenai keadaan yang diteliti.

\section{HASIL PENELITIAN DAN PEMBAHASAN}

\section{Gambaran Umum KOKAPURA "Selaparang"}

Awal berdirinya bernama "Koperasi Pegawai Negeri (KPN) Selaparang Dirjen Perhubungan Udara Kanwil VI Mataram berdasarkan Surat Keputusan Kepala Kantor Wilayah Departemen Koperasi Provinsi Nusa Tenggara Barat Nomor: 639/BH/XXII tanggal 29 November 1983 tentang Pendaftaran Akte Pendirian yang berkedudukan di Pelabuhan Udara Selaparang Kecamatan Mataram Lombok Barat Provinsi Nusa Tenggara Barat. Sejalan dengan mulai dikelolanya Pelabuhan Udara Selaparang oleh PT. Angkasa Pura I pada tahun 1995, berubah Namanya menjadi Koperasi Karyawan (KOPKAR) PURA SELAPARANG berdasarkan Surat Keputusan Menteri Koperasidan Pembinaan Pengusaha Kecil Republik Indonesia Nomor: 230/BH/PAD/KWK.23/IX/1996 tanggal 20 September 1996 tentang Pengesahan Perubahan Anggaran Dasar Koperasi, sehingga sampai sekarang namanya menjadi KOKAPURA SELAPARANG.

\section{Arus Kas Operasi (AKO)}

\section{Tabel 3}

\section{Hasil Perhitungan RasioArus Kas}

\begin{tabular}{|c|c|c|c|}
\hline TAHUN & $\begin{array}{l}\text { ARUS KAS OPERASI } \\
\text { (1) (Rp) }\end{array}$ & $\begin{array}{c}\text { KEWAJIBAN LANCAR } \\
\text { (2) (Rp) }\end{array}$ & $\begin{array}{l}\text { HASIL } \\
\text { (1): } \\
\text { (2) }\end{array}$ \\
\hline 2014 & $990,917,149.75$ & $1,060,355,168.94$ & 0.93 \\
\hline 2015 & $-155,340,828.56$ & $1,427,784,434.94$ & -0.11 \\
\hline 2016 & $587,528,807.63$ & $1,621,299,329.94$ & 0.36 \\
\hline 2017 & $1,011,895,503.89$ & $2,238,780,447.94$ & 0.45 \\
\hline 2018 & $1,149,967,026.54$ & $1,813,598,842.94$ & 0.63 \\
\hline
\end{tabular}

Sumber: Data Primer Diolah 
Dari hasil perhitungan di atas dapat diketahui bahwa arus kas operasi tahun 2014 - 2018 Rasio arus kas operasional mengalami fluktuatif.

\section{Cakupan Arus Dana (CAD)}

Tabel 4

Hasil PerhitunganCakupanArus Dana

\begin{tabular}{|r|c|r|c|c|r|}
\hline TAHUN & $\begin{array}{c}\text { EBIT } \\
(1)(\mathrm{Rp})\end{array}$ & $\begin{array}{c}\text { Bunga } \\
(2)(\mathrm{Rp})\end{array}$ & $\begin{array}{c}\text { Pajak } \\
(3)(\mathrm{Rp})\end{array}$ & $\begin{array}{c}\text { Deviden } \\
\text { Preferen } \\
(4)(\mathrm{Rp})\end{array}$ & $\begin{array}{c}\text { HASIL } \\
(\mathbf{1})+(\mathbf{2})+(\mathbf{3}):(\mathbf{4})\end{array}$ \\
\hline 2014 & $363,965,765.75$ & $50,514,684$ & $66,946,278$ & $35,642,338$ & $\mathbf{1 3 . 5 1}$ \\
\hline 2015 & $212,569,254.44$ & $28,542,268$ & $38,748,547$ & $20,858,483$ & $\mathbf{1 3 . 4 2}$ \\
\hline 2016 & $635,397,570.63$ & $7,021,189$ & $128,785,105$ & $60,793,496$ & $\mathbf{1 2 . 6 9}$ \\
\hline 2017 & $870,169,803.89$ & - & $178,338,957$ & $83,019,702$ & $\mathbf{1 2 . 6 3}$ \\
\hline 2018 & $1,018,145,998.54$ & - & $209,619,999$ & $129,364,160$ & $\mathbf{9 . 4 9}$ \\
\hline
\end{tabular}

Sumber: Data primer diolah

Dari hasil perhitungan di atas dapat dilihat bahwa rasio cakupan arus dana tahun 2014 - 2018. Dari kurun waktu lima tahun tersebut rasio cakupan dana mengalami perununan,

\section{Cakupan Kas terhadap Hutang Lancar}

\section{Tabel 5}

Hasil PeritunganCakupan Kas terhadapHutangLancar

\begin{tabular}{|r|r|c|c|r|}
\hline \multirow{2}{*}{ TAHUN } & Arus Kas Operasi & Deviden Kas & KewajibanLancar & \multicolumn{1}{|c|}{ Hasil } \\
\cline { 5 - 6 } & $(1)(\mathrm{Rp})$ & $(2)(\mathrm{Rp})$ & $(3)(\mathrm{Rp})$ & $\mathbf{( 1 ) + ( 2 ) : ( 3 )}$ \\
\hline 2014 & $990,917,149.75$ & $191,577,572$ & $1,060,355,168.94$ & $\mathbf{1 . 1 2}$ \\
\hline 2015 & $-155,340,828.56$ & $112,114,349$ & $1,427,784,434.94$ & $\mathbf{- 0 . 0 3}$ \\
\hline 2016 & $587,528,807.63$ & $326,765,041$ & $1,621,299,329.94$ & $\mathbf{0 . 5 6}$ \\
\hline 2017 & $1,011,895,503.89$ & $446,230,897$ & $2,238,780,447.94$ & $\mathbf{0 . 6 5}$ \\
\hline 2018 & $1,149,967,026.54$ & $493,200,860$ & $1,813,598,842.94$ & $\mathbf{0 . 9 1}$ \\
\hline
\end{tabular}

Sumber: Data primer diolah

Hasil perhitungan di atas dapat dilihat bahwa rasio cakupan arus kas terhadap hutang lancer tahun 2014-2018 Rasio Cakupan Kas Terhadap Hutang Lancar dari lima tahun tersebut dapat terlihat bahwa rasio berfluktuatif, 


\section{Pengeluaran Modal}

\section{Tabel 6}

Hasil PehitunganPengeluaran Modal

\begin{tabular}{|r|r|r|r|}
\hline \multicolumn{1}{|c|}{ TAHUN } & $\begin{array}{c}\text { Arus Kas Operasi } \\
(1)(\mathrm{Rp})\end{array}$ & $\begin{array}{c}\text { Peng. Modal } \\
(2)(\mathrm{Rp})\end{array}$ & $\begin{array}{c}\text { Hasil } \\
(1):(2)\end{array}$ \\
\hline 2014 & $990,917,149.75$ & $183,597,754$ & $\mathbf{5 . 4 0}$ \\
\hline 2015 & $-155,340,828.56$ & $86,953,362$ & $\mathbf{- 1 . 7 9}$ \\
\hline 2016 & $587,528,807.63$ & $441,353,215$ & $\mathbf{1 . 3 3}$ \\
\hline 2017 & $1,011,895,503.89$ & $312,582,933$ & $\mathbf{3 . 2 4}$ \\
\hline 2018 & $1,149,967,026.54$ & $325,717,435$ & $\mathbf{3 . 5 3}$ \\
\hline
\end{tabular}

Sumber: Data primer diolah

Dari hasil perhitungan di atas dapat dilihat bahwa Rasio pengeluaran modal pada Kokapura Selaparang tahun 2014-2018 berfluktuatif.

\section{Total Hutang}

\section{Tabel 7}

Hasil Perhitungan Total Hutang

\begin{tabular}{|r|c|c|r|}
\hline \multirow{2}{*}{ TAHUN } & Arus Kas Operasi & Total Kewajiban & \multicolumn{1}{c|}{ Hasil } \\
\cline { 2 - 4 } & $(1)(\mathrm{Rp})$ & $(2)(\mathrm{Rp})$ & $(1):(2)$ \\
\hline 2014 & $990,917,149.75$ & $1,473,287,458.94$ & $\mathbf{0 . 6 7}$ \\
\hline 2015 & $-155,340,828.56$ & $1,786,109,571.94$ & $\mathbf{- 0 . 0 9}$ \\
\hline 2016 & $587,528,807.63$ & $1,936,560,002.94$ & $\mathbf{0 . 3 0}$ \\
\hline 2017 & $1,011,895,503.89$ & $2,433,833,707.94$ & $\mathbf{0 . 4 2}$ \\
\hline 2018 & $1,149,967,026.54$ & $1,901,430,751.94$ & $\mathbf{0 . 6 0}$ \\
\hline
\end{tabular}

Sumber: Data primer diolah

Dari hasil perhitungan diatas dapat diketahui bahwa Rasio total hutang koperasi tahun 2014-2018 mengalami fluktuatif, 


\section{Arus Kas Bersih Bebas}

\section{Tabel 8}

Hasil PerhitunganArus Kas BersihBebas

\begin{tabular}{|c|c|c|c|c|c|}
\hline TAHUN & 2014 & 2015 & 2016 & 2017 & 2018 \\
\hline AKUN & & & & & \\
\hline Lababersih (1) & $297,019,488$ & $173,820,696$ & $506,612,466$ & $691,830,847$ & $808,526,000$ \\
\hline Bunga (2) & $50,514,684$ & $28,542,268$ & $7,021,189$ & & \\
\hline Depresiasi (3) & $196,218,246$ & $161,540,638$ & $243,075,103$ & $302,442,067$ & $392,664,175$ \\
\hline Deviden (4) & $35,642,338$ & $20,858,483$ & $60,793,496$ & $83,019,702$ & $129,364,160$ \\
\hline Peng. Modal (5) & $3,597,754.00$ & $36,953,362.00$ & $441,353,215.00$ & 312,58 & $325,717,435.00$ \\
\hline Total $(1,2,3,4,5)$ & $762,992,510$ & $471,715,447$ & $1,258,855,469$ & $1,389,053,260$ & $1,656,271,770$ \\
\hline Bunga (6) & $50,514,684$ & $28,542,268$ & $7,021,189$ & - & - \\
\hline $\begin{array}{l}\text { KewajibanJk } \\
\text { Panjang (7) }\end{array}$ & $412,932,290$ & $358,325,137$ & $315,260,673$ & $195,053,260$ & $87,831,909$ \\
\hline Total $(6,7)$ & $463,446,974$ & $386,867,405$ & $322,281,862$ & $195,053,260$ & $87,831,909$ \\
\hline Hasil & 1.65 & 1.22 & 3.91 & 7.13 & 18.86 \\
\hline
\end{tabular}

Dari hasil perhitungan di atas dapat diketahui bahwa Rasio arus kas bersih bebas pada Kokapura Selaparang tahun 2014-2018 terus mengalami

fluktuatif.

\section{KecukupanArus Kas}

Tabel 9

Hasil Perhitungan Kecukupan Arus Kas

\begin{tabular}{|l|r|r|r|r|r|}
\hline \multicolumn{1}{|c|}{ TAHUN } & \multicolumn{1}{|c|}{2014} & \multicolumn{1}{c|}{2015} & \multicolumn{1}{c|}{2016} & \multicolumn{1}{c|}{2017} & \multicolumn{1}{c|}{2018} \\
\hline AKUN & $363,965,765.75$ & $212,569,254.44$ & $635,397,570.63$ & $870,169,803.89$ & $1,018,145,998.54$ \\
\hline Bunga (2) & $50,514,684.00$ & $28,542,268.00$ & $7,021,189.00$ & - & - \\
\hline Pajak (3) & $66,946,278.00$ & $38,748,547.00$ & $128,785,105.00$ & $178,338,957.00$ & $209,619,999.00$ \\
\hline Peng. Modal (4) & $183,597,754.00$ & $86,953,362.00$ & $441,353,215.00$ & $312,582,933.00$ & $325,717,435.00$ \\
\hline Total (1,2,3,4) & $62,907,049.75$ & $58,325,077.44$ & $58,238,061.63$ & $379,247,913.89$ & $482,808,564.54$ \\
\hline $\begin{array}{l}\text { Rata-rata } \\
\text { KewajibanJk }\end{array}$ & & & & & \\
Pendek (5) & $1,452,363,644.56$ & $1,452,363,644.56$ & $1,452,363,644.56$ & $1,452,363,644.56$ & $1,452,363,644.56$ \\
\hline Hasil (total/(5)) & $\mathbf{0 . 0 4}$ & $\mathbf{0 . 0 4}$ & $\mathbf{0 . 0 4}$ & $\mathbf{0 . 2 6}$ & $\mathbf{0 . 3 3}$ \\
\hline
\end{tabular}

Dari hasil perhitungan diatas dapat diketahui bahwa Rasio kecukupan arus kas koperasi pada tahun 2014-2018 cenderung mengalami peningkatan walaupun tipis, hasil tertingg iterjadi pada tahun 2018 yakni sebesar 0,33. 


\section{KESIMPULAN DAN SARAN}

\section{KESIMPULAN}

a. Pada Rasio Arus Kas Operasi (AKO) 5 (lima) tahun terakhir mengalami fluktuatif dan masih dibawah 1 (satu) yang dikhawatirkan koperasi ini bermasalah terhadap penurunan likuiditas, namun rasio ini sudah mengarah pada hasil yang positif.

b. Pada Rasio Cakupan Arus Dana (CAD) dari tahun 2014-2018 memiliki kemampuan yang baik dalam membayar komitmen-komitmennya, karena telah memenuhi standar yakni di atas 1 , walaupuan ada indikasi mengalami penurunan dari tahun 2014-2018.

c. Pada Rasio Cakupan Kas terhadap HutangLancar (CKHL) dalam kurun lima tahun terakhir mengalami fluktuatif namun tetap dikatakan kurang baik karena belum mampu memenuhi standar yakni di atas 1, yang berarti arus kas operasi tidak mampu membayar kewajiban lancar, walaupun demikian rasio ini dari tahun ketahun terus mengarah kepositif berupa kenaikan.

d. Pada Rasio Pengeluaran Modal (PM) dalam kurun 5 (lima) tahun terakhir mengalami fluktuatif namun dapat dikatakan baik, karena rasio ini telah memenuhi standar diatas 1, yang berarti arus kas operasi dapat membiayai pengeluaran modalnya.

e. Pada Rasio Total Hutang (TH) dari tahun 2014-2018 mengalami fluktuatif namun tetap dikatakan kurang baik karena belum mampu memenuhi standar yakni di atas 1, yang berartiarus kas operas itidak mampu membayar total kewajiban, walaupun demikian rasio ini dari tahun ketahun terus mengarah kepositif berupa kenaikan.

f. Pada Rasio Arus Kas Bersih Bebas (AKBB) dalam kurun 5 (lima) tahun terakhir mengalami fluktuatif namun dapat dikatakan baik, karena rasio ini telah memenuhi standar diatas 1, yang berarti koperasi dapat membiayai kewajiban lancar yang akan jatuh tempo

g. Pada Rasio Kecukupan rus Kas (KAK) lima tahun terakhir mengalami fluktuatif namun tetap dikatakan kurang baik karena belum mampu memenuhi standar yakni di atas 1 , yang berarti pada tahun mendatang berkemungkinan tidak dapat memenuhi kewajibannya karena kas yang tersedi auntuk memenuhi kewajiban tidak mencukupi, namun pada rasio ini terus mengarah kepositif yakni berupa peningkatan nilai rasio dari tahun ketahun.

Oleh karena itu dalam hal ini dikarenakan kemampuan koperasi mengelola arus kas operasi masih kurang optimal. Dari kinerja keuangan Kokapura Selaparang tahun 2014-2018 di nilai dari rasio laporan arus kas cenderung berfluktuatif. 


\section{SARAN}

1. Untuk mengatasi rasio arus kas operasi yang rendah Kokapura Selaparang dapat melakukan beberapa opsi guna meningkatkan kas operasinya salah satunya dengan cara mempercepat periode penagihan piutang usaha dan piutang lainnya serta mempercepat perputaran penyaluran kredit yang dilakukan.

2. Rasio Cakupan Kas Terhadap Hutang Lancar dari lima tahun tersebut dapat terlihat bahwa terjadi kenaikan serta penurunan cakupan arus kas terhadap hutang lancar. Alangkah baiknya jika Kokapura Selaparang tidak hanya menitik beratkan aktivanya hanya pada akun piutang saja akan tetapi pada kas juga sehingga dalam memenuhi kewajiban jangka pendeknya agar lebih cepat terpenuhi.

3. Dari perhitungan di atas dapat diketahui jika koperasi memiliki nilai rasio total hutang yang rendah, sebaiknya perusahaan meningkatkan penjualan agar dapat menghasilkan kas lebih banyak sehingga laba perusahaan meningkat dan mengurangi jumlahhutang.

4. Perusahaan ini memiliki rasio kecukupan arus kas yang buruk, karena tidak dapat memenuhi kewajibannya, sebaiknya perusahaan mempercepat periode perputaran persediaan untuk meningkatkan arus kas masuk perusahaan daria ktivitas operasi agar rasio ini dapat membayar utangnya

\section{DAFTAR PUSTAKA}

Afrina. 2013. Analisis Laporan Arus Kas dalam Menilai Kinerja Keuangan pada Koperasi Unit Desa Sumber Makmur Kec. Kepenuhan. Jurnal Akuntansi

Anoraga, Pandji dan Ninik Widiyanti. 2007. Dinamika Koperasi. Jakarta: Rineka Cipta.

Arifin, Sitio dan Halomon Tamba. 2001. Koperasi Teori dan Praktek. Jakarta: Erlangga

Afiq, Much. Syahrul. 2017. Analisis Laporan Arus Kas untuk Mengukur Likuiditas pada KSU Sri Lestari. Kediri: Simki-Economic Vol. 02 No. 03 Tahun 2018 ISSN : 2599-0748 UN PGRI

Darsono\&Ashari. 2005.

PedomanPrakrisMemahamiLaporanKeuangan.Yogyakarta: Andi.

Frase, Lyn dan AilenMrmiston, 2004. Memahami Laporan Keuangan.Edisi Keenam. Jakarta. PT. Indeks.

Hery. 2015. Analisis Laporan Keuangan. Yogyakarta: Center For Academic Publishing Service

IkatanAkuntan Indonesia (IAI). 2013. Standar Akuntansi Keuangan Entitas Tanpa Akuntabilitas Publik.Cetakan III Jakarta: Ikatan Akuntan Indonesia (IAI). 
Juniarti, Farida Utami. 2016. Analisis Laporan Arus Kas pada PT. IndosanTbk. Semarang: Univ. Dian Nuswantoro.

Jusup, Haryono. 2011. Dasar - Dasar Akuntansi. Yogyakarta: Sekolah Tinggi Ilmu Ekonomi YKPN.

Kieso, Donald E, Jerry J. Weygandt and Terry D. Warfield. 2008. Akuntansi Intermediate. Edisikeduabelas Jilid 1. Jakarta: Erlangga.

Kieso, Donald E., Jerry J. Weygandt, dan Terry D. Warfield, 2002, Akuntansi Intermedite, Terjemahan Emil Salim. Edisi Kesepuluh, Jilid Tiga. Jakarta: Erlangga.

Kismati, Alfi. 2019. Analisis Laporan Aru Kas dalam Menilai Kinerja Keuangan Koperasi Wanita Al-Barokah Kec. SokoKab. Tuban. Surabaya: Jurnal Akuntansi, UIN SunanAmpel

Mamduh M. Hanafi dan Abdul Halim. 2014. AnalisisLaporanKeuangan. EdisiKeempat. Yogyakarta: UPP STIM YKPN.

Marfu'ah. 2016. Analisis Laporan Arus Kas dalam Menilai Kinerja Keuangan pada Perusahaan (Studi Kasus PTPN II Tanjung Morowa). Medan: Jurnal Manajemen. UIN SUMUT

Prihadi, Toto. 2011. Praktis Memahami Laporan Keuangan Sesuai IFRS\&PSAK. Jakarta: PPM.

Siahaan, Delimarini. 2017. Analisis Laporan Arus Kas Untuk Menilai Kinerja Keuangan pada Koperasi Kredit Sejahtera (Credit Union) Tanjung Marulak Kec. Rambutan Kota Tebing Tinggi. Tebing Tinggi: Univ. Medan Area.

Subani. 2015. Analisis Arus Kas untuk Mengukur Kinerja Keuangan.Lumajang: Jurnal WIGA Vol. 5 No. 1, Maret 2015 ISSN NO 2088-0944. STIE Widya Gama.

Sugiyono. 2014. Metode Penelitian Kuantitatif, Kualitatif dan R\&D. Bandung: Alfabeta.

Rudianto. 2012. Pengantar Akuntansi, Konsep dan Teknik Penyusunan Laporan Keuangan. Jakarta: Erlangga.

Warongan, Megi S Jona. 2018. Analisis Rasio Arus Kas dalam Menilai Kinerja Keuangan pada PT. PLN (Persero) Wilayah Suluttenggo. Manado: Jurnal RisetAkuntansi Going Concern 13(2), 2018, 453-463. Univ. Sam Ratulangi.

Undang-Undang Republik Indonesia Nomor 25 Tahun 1992 tentang Perkoperasian 